\title{
Formation process and properties of hydrogen-producing granular sludge in UASB reactor
}

\author{
Lili Yin, Shuang Liu, Mengyi Wang, Wencong Ju, Donghui Wei, Wenzhe Li \\ (College of Engineering, Northeast Agricultural University, Harbin 150030, China)
}

\begin{abstract}
The granular sludge of microbial fermentation systems includes various biomass-degrading enzymes and different microflora, which have significant impacts on the degradation of biomass and the stability of the system. An up-flow anaerobic sludge blanket (UASB) reactor was used to grow hydrogen-producing granular sludge. The results showed that the formation of the granular sludge underwent four stages, i.e., flocculation of the sludge, formation of the flocculent sludge, swelling of the flocculent sludge, and formation of the granular sludge. The formed granular sludge mostly had regular spherical and ellipsoidal shapes with a fractal dimension of $2.08 \pm 0.4$; the settling velocities were $0.84 \mathrm{~cm} / \mathrm{s}$ to $1.96 \mathrm{~cm} / \mathrm{s} \mathrm{in}$ water, the porosity was $0.67-0.95$. The shear sensitivity $\left(K_{s s}\right)$ of the granular sludge was 0.1152 . The granular sludge had a culture cycle of approximately $70 \mathrm{~d}$ and a hydrogen yield of $1.09 \mathrm{~mol} \mathrm{H}_{2} / \mathrm{mol}$ glucose.
\end{abstract}

Keywords: anaerobic fermentation, UASB reactor, granular sludge, hydrogen

DOI: $10.25165 /$ j.ijabe.20181105.4255

Citation: Yin L L, Liu S, Wang M Y, Ju W C, Wei D H, Li W Z. Formation process and properties of hydrogen-producing granular sludge in UASB reactor. Int J Agric \& Biol Eng, 2018; 11(5): 224-229.

\section{Introduction}

In recent years, the hydrogen production from the anaerobic fermentation of biomass has received widespread attention ${ }^{[1-3]}$. Compared with the use of continuous stirred tank reactor for the hydrogen production from anaerobic fermentation, the UASB reactor can maintain the stability of the system in the fermentation process, thus having higher biomass treatment efficiency and hydrogen yield ${ }^{[4-6]}$. This is because the microorganisms inside the UASB reactor can form granular sludge with regular shapes through the self-immobilization process. The microflora and the various enzymes comprising the granular sludge optimize the distance between the intermediate and final metabolites and the different microflora, thus forming a microecosystem that can self-adjust ${ }^{[7,8]}$. The hydrogen production by the granular sludge and the macroscopic operating performance has gradually become a hot research topic. Researchers investigated the physical and chemical properties of granular sludge. Some factors of the hydrogen yield had also been researched. For example, substrate, organic loading rate, influent upward velocity, sodium ion, etc affected the hydrogen production granular ${ }^{[9-12]}$. Li et al. ${ }^{[13]}$ developed an analytical method for the determination of the settling property of granular sludge. $\mathrm{Yu}$ et al. $^{[14]}$ investigated the influencing factors in the granular sludge formation process.

Received date: 2018-03-23 Accepted date: 2018-09-11

Biographies: Lili Yin, $\mathrm{PhD}$ candidate, research interests: biomass transformation and energy utilization, Email: yinlili2015@163.com; Shuang Liu, Lecturer, research interests: biomass transformation and microorganism utilization, Email: liushuang@neau.edu.cn; Mengyi Wang, Graduate candidate, research interests: biomass fermentation, Email: wangmengyi66@163.com; Wencong Ju, Graduate candidate, research interests: biomass transformation and microorganism utilization, Email: juwencong@163.com; Donghui Wei, Lecturer, research interests: electric automation, Email: 372162666@qq.com.

*Corresponding author: Wenzhe Li, Professor, research interests: biomass transformation and energy utilization. Northeast Agricultural University, No.600 Changjiang Street, Xiangfang District, Harbin 150030, China. Tel: +86 13936491559, Fax:+86-451-55191985, Email: liwenzhe9@163.com.
However, there is stillroom to investigate the formation and properties of granular sludge in the hydrogen-producing anaerobic fermentation process. In the present study, the UASB reactor was used to grow hydrogen-producing granular sludge. The formation process of the granular sludge and the mechanism were investigated. In addition, scanning electron microscope (SEM), Stokes' law, and a hydraulic shear test were used to analyse the structure, settling property, and shear sensitivity of the mature granular sludge. The results can be used to provide parameters to improve the biomass treatment efficiency, hydrogen production capability, and stable operation of the fermentation system.

\section{Materials and Methods}

\subsection{Feedstock and seeding source}

The digestion sludge was obtained from an anaerobic digester in the Northeast Agricultural University and fed cattle manure for biogas production. To enrich the hydrogen-producing microorganisms, the digestion sludge was thermally treated in a boiling water bath for $30 \mathrm{~min}$ and then used as the seed sludge. The $\mathrm{pH}$, alkalinity, and concentration of volatile suspended solid (VSS) of the seed sludge were 7.5, $1.9 \mathrm{~g}$ of $\mathrm{CaCO}_{3} / \mathrm{L}$, and $16.5 \mathrm{~g} / \mathrm{L}$, respectively. The synthetic organic wastewater was used as the substrate for the UASB reactor, in which the glucose concentration was $9.3 \mathrm{~g} / \mathrm{L}$. To improve the buffer capacity of the reactor, $\mathrm{NaHCO}_{3}$ was added to the organic wastewater to have a concentration of $5 \mathrm{~g} / \mathrm{L}$. The concentrations of $\mathrm{NH}_{4} \mathrm{Cl}, \mathrm{KH}_{2} \mathrm{PO}_{4}$, and $\mathrm{FeCl}_{2} \cdot 4 \mathrm{H}_{2} \mathrm{O}$ added to the organic wastewater were controlled to obtain a COD:N:P:Fe ratio of $100: 5: 1: 0.33$. The organic wastewater also contained the following nutrients, $\mathrm{mg} / \mathrm{L}$ : $\mathrm{MgCl}_{2} \cdot 6 \mathrm{H}_{2} \mathrm{O}, 100 ; \mathrm{CaCl}_{2} \cdot 2 \mathrm{H}_{2} \mathrm{O}, 75 ; \mathrm{Na}_{2} \mathrm{MoO}_{4} \cdot 4 \mathrm{H}_{2} \mathrm{O}, 0.01 ; \mathrm{H}_{3} \mathrm{BO}_{3}$, $0.05 ; \mathrm{MnCl}_{2} \cdot 4 \mathrm{H}_{2} \mathrm{O}, 0.5 ; \mathrm{ZnCl}_{2}, 0.05 ; \mathrm{CuCl}_{2}, 0.03 ; \mathrm{NiCl}_{2} \cdot 6 \mathrm{H}_{2} \mathrm{O}$, $0.05 ; \mathrm{CoCl}_{2} \cdot 2 \mathrm{H}_{2} \mathrm{O}, 0.5$ and $\mathrm{Na}_{2} \mathrm{SeO}_{3}, 0.05^{[15]}$.

\subsection{Experimental setup}

Figure 1 shows the schematic of the structure of fermentation setup. The fermentation apparatus was composed of the UASB reactor, peristaltic pump, liquid-storage tank, and gas-collection bag; the reactor had a working volume of $17 \mathrm{~L}$. Seed sludge was 
seeded to the UASB reactor and operated in continuous fermentation. The fermentation temperature was $(35 \pm 1)^{\circ} \mathrm{C}$; the hydraulic retention time (HRT) was $6 \mathrm{~h}$.

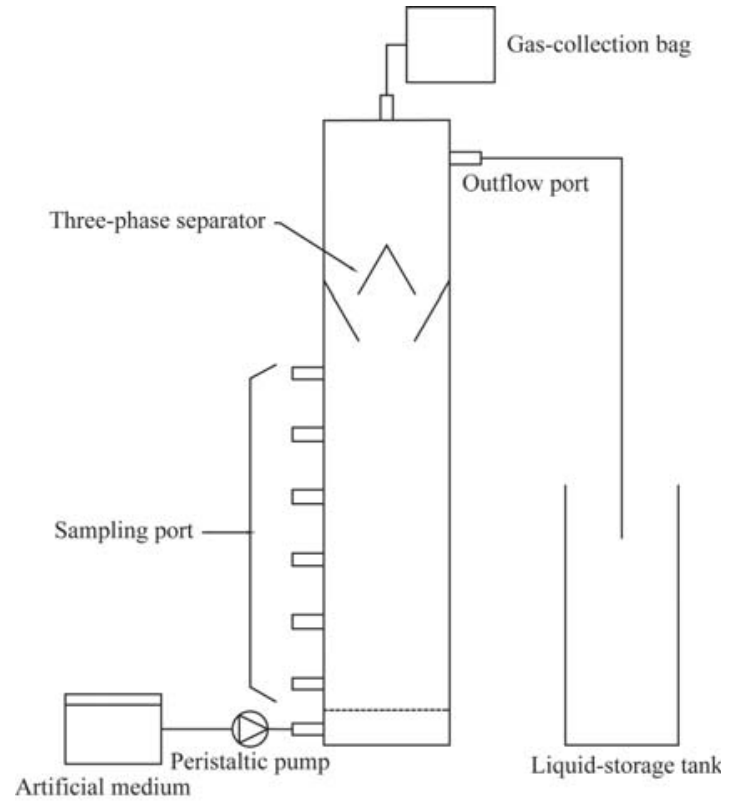

Figure 1 Schematic of the structure of UASB reactor

\subsection{Analytical and methods}

The concentrations of hydrogen, ethanol, and volatile fatty acids (VFAs, such as acetic acid, propionic acid, and butyric acid) were determined by gas chromatography (GC-6890N, Agilent, USA $)^{[16]}$. The diameter of the granular sludge was measured and calculated using an optical microscope (Leica DM4000B) and image analysis software (leicaQin 3.0). The measurement of the dry weight of granular sludge was similar to the total solid measurement. The microstructure of the spatial structure was characterized using SEM (Hitachi S-3400N, Japan) ${ }^{[17]}$.

The settling property was analysed by settling experiments and Stokes' law ${ }^{[18]}$; the velocity of the settling granules in the last $10 \mathrm{~cm}$ was used as the actual settling velocity $(\mathrm{U})$ of the granular sludge. The theoretical settling velocity $(U s)$ of the granular sludge can be calculated from Equation (1). The porosity $(\varepsilon)$, fractal dimension $(D)$ and the fluid collection efficiency $(\eta)$ of granular sludge can be calculated based on Equations (2)-(4):

$$
U S=\left[\frac{4 g\left(\rho_{a}-\rho_{1}\right) d}{3 \rho_{1} C_{d}}\right]^{\frac{1}{2}}
$$

where, $\rho_{a}$ is the density of the granular sludge; $\rho_{1}$ is the density of liquid; $d$ is the diameter of the granular sludge, and $C_{d}$ is the viscosity.

$$
\varepsilon=1-\frac{6 f W_{d}}{\pi \rho_{a} d^{3}}
$$

where, $W_{d}$ is the dry weight of the granules; the determination of the coefficient $f$ can be performed according to the theoretical study by $\mathrm{Li}$ et al. ${ }^{[19]}$

$$
\eta=\frac{9-(\S-\tan h(\S))}{2 \S^{2}+3(\S-\tan h(\S))}
$$

$\S$ can be calculated from Equation (5):

$$
\Gamma=\frac{U}{U s}=\frac{\S}{\S-\tan h(\S))}+\frac{3}{2 \S^{2}}
$$

The shear strength of the granular sludge can be analysed based on the experimental method of Pereboom. The estimation of equilibrium concentration of dispersed particles in the supernatant of sheared sludge sample $\left(m_{d, \infty}\right)$ can be fitted using the dispersion equation (Equation (6)).

$$
m_{d, t}=m_{d, \infty}+\left(m_{d, 0}-m_{d, \infty}\right) \frac{6}{\pi^{2}} \sum_{N=1}^{9} \frac{1}{N^{2}} e^{-N^{2} D_{f} t}
$$

where, $m_{d, 0}$ and $m_{d, t}$ are the concentrations, $\mathrm{g} / \mathrm{L}$ of $\mathrm{t}$ dispersed particles in the beginning and at time $t ; D_{f}$ is the effective diffusion coefficient; $N$ is an integer.

The shear sensitivity $\left(K_{s s}\right)$ can be calculated from Equation (7), where $m_{T}$ is the total solid mass of the sludge suspension.

$$
K_{s s}=\frac{m_{d, \infty}}{m_{T}}
$$

\section{Results and discussion}

\subsection{Formation process of granular sludge}

Granular sludge is normally a cell cluster formed in the application of the UASB reactor, which has a regular shape and definite surface area, a high mechanical strength and specific activity. In the $110 \mathrm{~d}$ test period, the granulation of sludge underwent four stages, i.e., flocculation of sludge, formation of flocculent sludge, swelling of flocculent sludge, and formation of granular sludge.

The first stage of flocculation lasted for approximately $20 \mathrm{~d}$. Figure $2 \mathrm{a}$ shows the state of the sludge at day 5, and the overall state of the sludge at days 1-20 is as shown in Figure $2 \mathrm{~b}$. When the seed sludge was under a hydraulic load of $0.14 \mathrm{~m}^{3} /\left(\mathrm{m}^{2} \cdot \mathrm{h}\right)$, the collision frequency of the sludge increased with the growth of microorganisms and the increase in the concentration of extracellular polymeric substances (EPS), and the sludge began to flocculate and grow. The unflocculated sludge flew out of the reactor along with the movement direction of the fermentation broth. The sludge had a deep apparent colour, which is similar to the colour of the seed sludge.

In the second stage, the flocculent sludge was formed; this stage lasted for approximately $30 \mathrm{~d}$. Figure $2 \mathrm{~b}$ shows the state of the sludge on day 20. Under the impact of the upflow fluid, the flocculent sludge further aggregated to present a catkin-like morphology, as shown in Figure 2b. The flocculent sludge had small diameters and a certain settling velocity. The flocculent sludge gradually increased on days 20-35. Afterwards, the fermentation system was stably operated for approximately $15 \mathrm{~d}$. The apparent colour of the sludge was changed from dark to light, indicating that the total density of microorganisms inside the reactor increased. Thus, the three-phase separator did play a role in this stage. Although there was an outflow of sludge, the outflow of the inactivated sludge was greater than that of the activated sludge, resulting in a colour change.

In the third stage, the flocculent sludge swelled; this stage lasted for approximately $20 \mathrm{~d}$. Conglutination of the sludge appeared on days 50-65, exhibiting swelling of the sludge. The flocculent sludge that was not conglutinated or had low degree of conglutination still possessed a certain settling velocity and was concentrated on the bottom of the reactor. However, the flocculent sludge with a large area of conglutination, as evidenced swelling, exhibited a decreased settling velocity and a large quantity floated to the top of the reactor. Figure $2 \mathrm{c}$ shows the state of the sludge fermented on day 60. The three-phase separator had no appreciable impact on the separation of the sludge. The floated sludge was accumulated on the periphery of the 
three-phase separator and gradually flew out of the reactor with the water flow from the overflow port. The run-off of the sludge also carried away gases encapsulated in the sludge, thus affecting gas production efficiency. On the 65th-70th days of the reaction, the large-area swelling of the sludge ended, and the flow-out of the flocculent sludge gradually decreased. At this time, the apparent colour became even lighter and was greyish white, indicating that the total density of microorganisms inside the reactor further increased.

In the fourth stage, the granular sludge formed. When the test time was approximately $70 \mathrm{~d}$, the EPS accumulated inside the flocculent sludge, and the contact between microorganisms became closer. As a result, the microorganism aggregate-granular sludge, with a dense structure and regular shape, started to form on the bottom of the reactor. In this stage, the granular sludge rapidly increased and exhibited high settling velocity. The granular sludge floated with gas and started to settle when contacting the three-phase separator. Therefore, the impact of the three-phase separator was significant. The biological activity of granular sludge in the reactor reached an equilibrium state. Figure $2 \mathrm{~d}$ shows the state of sludge on day 90. A clear boundary appeared between the granular sludge region and supernatant region inside the reactor. The colour of the granular sludge was close to white, basically the same as that of the bacteria. The fermentation system entered a stable operation period and exhibited a high and stable hydrogen-producing performance.
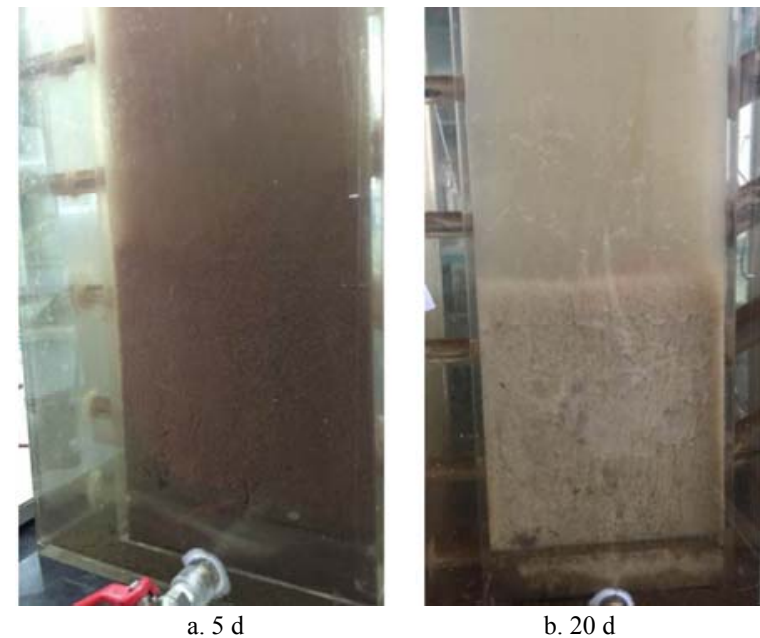

b. $20 \mathrm{~d}$
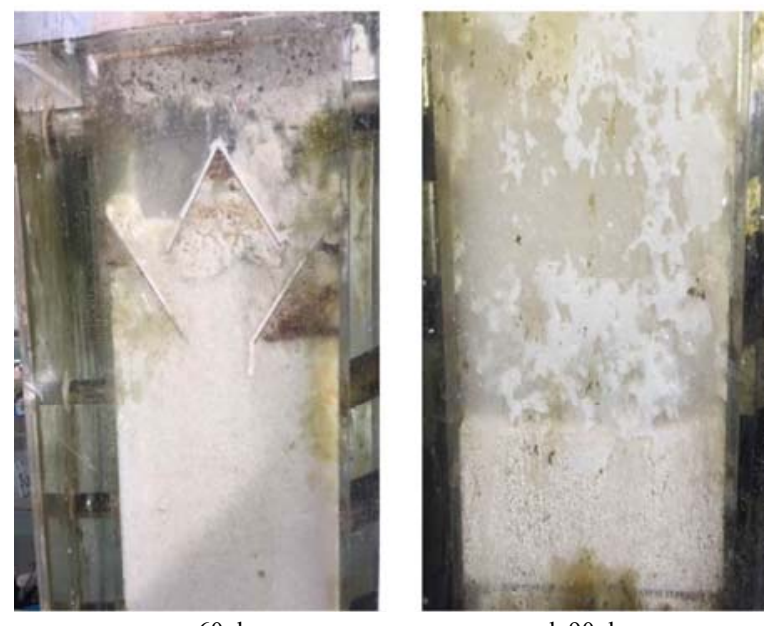

d. $90 \mathrm{~d}$

Figure 2 Morphological of sludge at different days

The selection pressure (hydraulic load and gas load) and EPS played an important role in the granulation of sludge ${ }^{[20]}$. Under low selection pressure, the granular sludge in the anaerobic reactor can not be stably operated for a long time, and usually, there will be a loss of a large amount of sludge $\mathrm{e}^{[21]}$. The EPS in the granular sludge act as bridges among the bacteria ${ }^{[22]}$. Liu et al. ${ }^{[23]}$ found that the EPS concentration significantly impacted the zeta potential and the contact angle of the microorganism system, thus affecting the flocculation of bacteria. The increase of EPS promotes the growth of granular sludge ${ }^{[24]}$. In the initial stage of the test, the specific activity of bacteria in the sludge was low. Correspondingly, the concentration of metabolites of bacteria was low. Figure 3 shows the time dependence of the concentrations of EPS and organic acids/alcohols produced from the bacterial metabolism. On days 1-30, the EPS concentration was always below $60 \mathrm{mg} / \mathrm{g}$, the gas production rate was low relative to the whole fermentation process, and the gas load was always below $0.08 \mathrm{~m}^{3} /\left(\mathrm{m}^{2} \cdot \mathrm{h}\right)$. Lacking the adhesion of EPS and the promotion of selection pressure, the generated sludge aggregate mostly exhibited a large specific surface area and a low mechanical strength. Therefore, the sludge aggregate produced in the first $30 \mathrm{~d}$ of fermentation was structurally unstable flocculent sludge. Then, the EPS concentration in the sludge increased to $150 \mathrm{mg} / \mathrm{g}$, and the gas load also increased to below $0.31 \mathrm{~m}^{3} /\left(\mathrm{m}^{2} \cdot \mathrm{h}\right)$. At this time, the structure of the sludge aggregate was also unstable. On the 70th day of fermentation, the concentration of EPS produced from the bacterial metabolism increased to $237 \mathrm{mg} / \mathrm{g}$, and the gas load in the reactor increased to approximately $0.43 \mathrm{~m}^{3} /\left(\mathrm{m}^{2} \cdot \mathrm{h}\right)$. At this selection pressure and EPS concentration, the sludge aggregate exhibited a dense structure and regular shape.

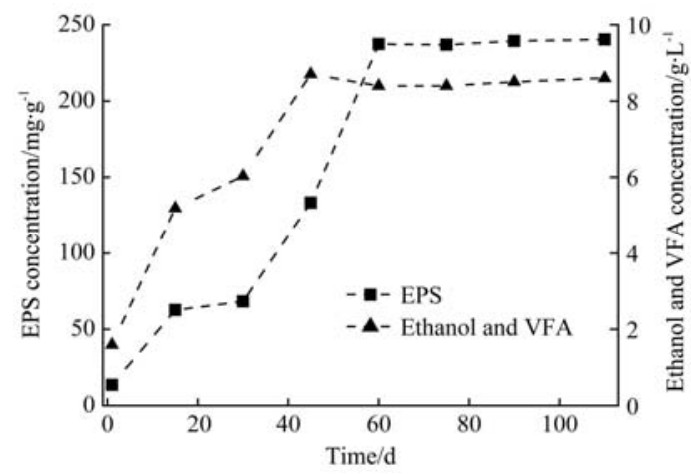

Figure 3 Daily variations of the EPS concentrations inside sludge and the organic acids/alcohols in the supernatant

\subsection{Spatial structure of granular sludge}

As shown in Figure 4, the granular sludge exhibited a relatively regular spherical or ellipsoidal shape with a size of 1$5 \mathrm{~mm}$. Figure 6 shows the SEM images of the granular sludge. The granular sludge exhibited a mesh structure with a clear hierarchy. The lines that comprise the mesh structure exhibited two forms. The first line was formed from head-tail connection of single bacteria; the diameter of the line was approximately $1.05 \mu \mathrm{m}$. The second line was formed from the bundling and adhesion of multiple bacteria; the diameter of the bundled line was usually greater than $3.01 \mu \mathrm{m}$. The nodes of the mesh structure consisted of the multiple bacteria and the EPS produced from bacterial metabolism. The mesh lines composed of the bundled growth of bacteria and the nodes composed of the bacteria bound by EPS increased the stability of the mesh structure.

The basic mechanism of granular sludge formation process can be inferred from the spatial structure and existing forms of the granular sludge: the hydrogen-producing and acid-producing fermentation microorganisms reproduced and grew through binary 
fission. The fission is along the cross-section perpendicular to the long $\operatorname{axis}^{[25]}$. Therefore, the hydrogen-producing bacteria and acid-producing bacteria reproduced and grew to form the head-tail connecting line structure, as shown in Figure 5, the state of the bacteria observed at a magnification of $\times 1000$ under an optical microscope. Under the disturbance of the flow, the long-line structure moved upward and downward and formed small windings, which further formed small aggregates of flocculent sludge through

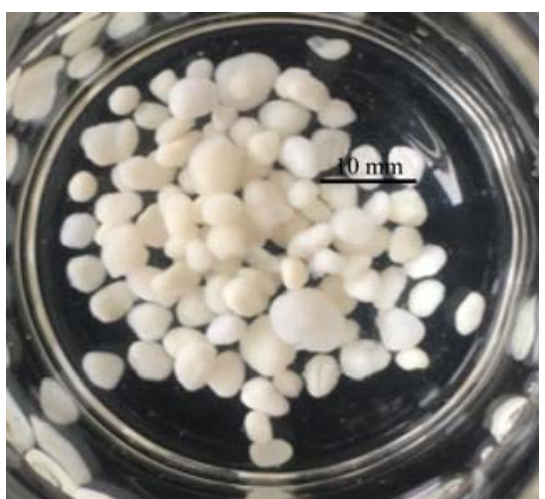

Figure 4 Granular sludge shape

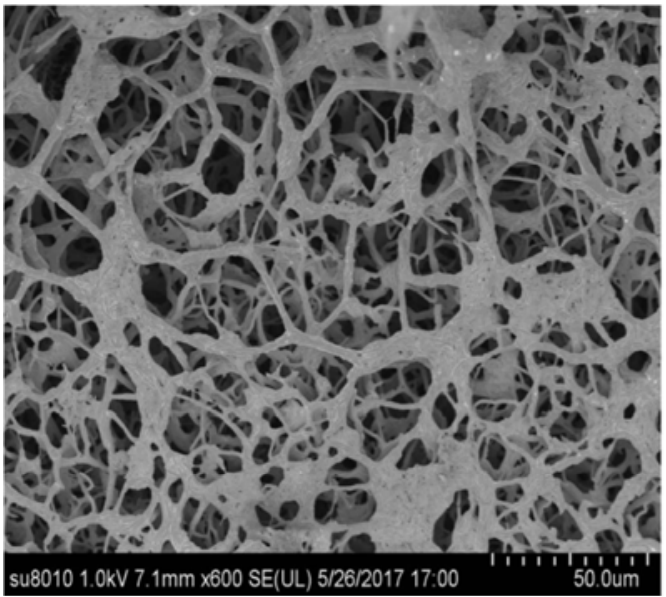

a. $\times 600$ the binding of EPS. With the increase of EPS concentration in the flocculent sludge and the accelerated movement of the fluid, the contact points of the line structure increased, and the winding of the lines became denser. At the same time, the other fermentation bacteria in the fermentation broth continuously entered the mesh structure due to the fluid and used the mesh structure as their support for further metabolism and growth, forming structurally stable and regularly shaped granular sludge.

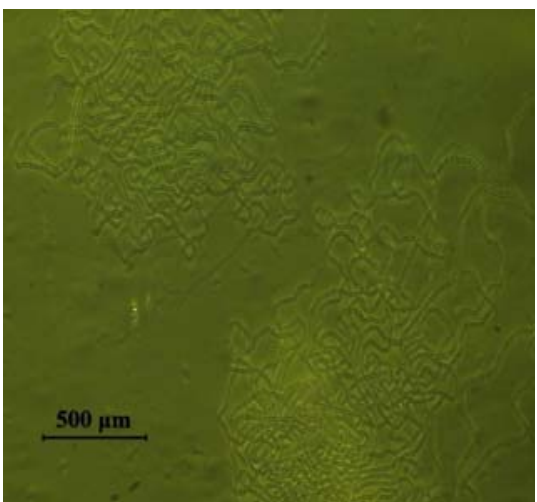

State of bacterial observed under optical microscope $(\times 1000)$

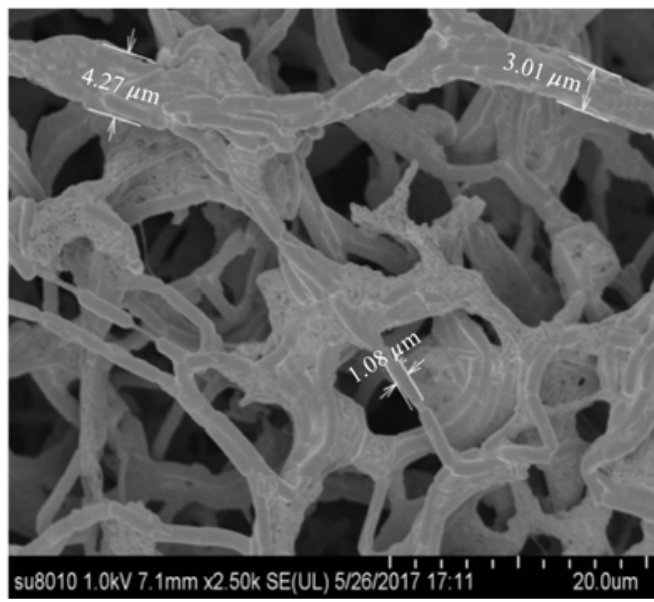

b. $\times 2500$

Figure 6 SEM images of granular sludge

\subsection{Continuous hydrogen yield performance}

The granulation of the sludge exhibited different hydrogen yield behaviours (Figure 7). In the first stage of the granulation of sludge, the hydrogen yield was approximately $0.42 \mathrm{~mol} \mathrm{H}_{2} / \mathrm{mol}$ glucose and started to decrease on day 10 due to the loss of digestion sludge in the reactor. This observation is similar to that by Hulshoff $\mathrm{Pol}$ et $\mathrm{al}^{[26]}$, i.e., in the initial stage of the granulation of sludge, there will be loss of sludge in the reactor under the dual interaction of gas flow rate and inlet water flow rate. In the second stage, the formation of the flocculent sludge in the reactor largely improved the hydrogen-production performance, and the hydrogen yield was approximately $0.91 \mathrm{~mol} \mathrm{H}_{2} / \mathrm{mol}$ glucose. However, when the fermentation proceeded to the third stage, the loss of flocculent sludge carried away gases, resulting in a decrease of hydrogen yield. In the third stage of the experiment, the granular sludge was formed and rapidly increased. At this stage, the fermentation system started to exhibit stable operation, and the hydrogen yield was approximately $1.09 \mathrm{~mol} \mathrm{H}_{2} / \mathrm{mol}$ glucose. The various indexes of the reactor after stabilization of fermentation are listed in Table 1. To summarize, in the UASB reactor, the granulation of the sludge and the stable operation of the anaerobic hydrogen production system require a certain starting time. The startup period of the granular sludge is approximately $70 \mathrm{~d}$, and the glucose conversion was above $98.46 \%$.

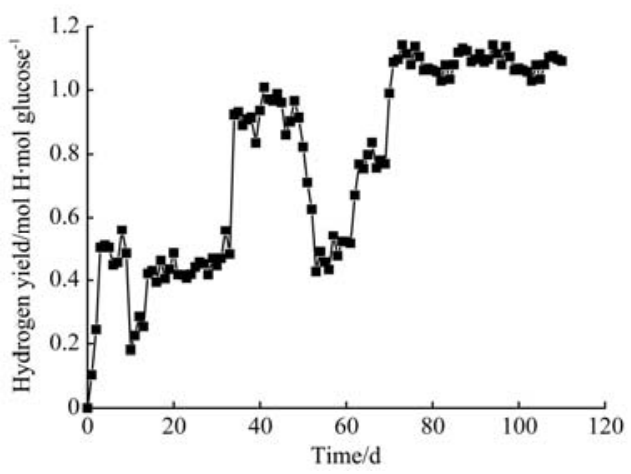

Figure 7 Daily hydrogen yield in the UASB reactor

Table 1 Parameters on average $\mathrm{H}_{2}$ fermentation performance

\begin{tabular}{ccccc}
\hline Parameters & $\mathrm{pH}$ & $\mathrm{ORP}$ & $\mathrm{NH} \mathrm{H}_{4} \mathrm{~N} / \mathrm{mg} \mathrm{N} \cdot \mathrm{L}^{-1}$ & Glucose conversion $/ \%$ \\
\hline Value & $5.23 \pm 0.2$ & $-0537 \pm 5$ & $273 \pm 3$ & 98.46
\end{tabular}

\subsection{Settling property of granular sludge}

Figure $8 \mathrm{a}$ shows that the dry mass of the granular sludge increased with increasing diameter, the dry weight of the granular 
sludge was 130-900 $\mu \mathrm{g}$. Based on the slope of the log relationship between dry weight and diameter, the fractal dimension of the granules was calculated $(D=2.08 \pm 0.42)$, indicating that the granular sludge had a fractal structure. The porosity calculated from Equation (2) was $0.67-0.95$. As shown in Figure 8b, the porosity of granular sludge was mostly greater than 0.8 and increased with increasing diameter. Figure 9a shows that the actual settling velocity of the granular sludge was $0.84-1.96 \mathrm{~cm} / \mathrm{s}$. In addition, the settling velocity increased with increasing particle diameter. The actual settling velocity was slightly greater than the settling velocity of the porous but impermeable particles $(0.59-1.56 \mathrm{~cm} / \mathrm{s})$ calculated using Stokes' law. Figure $9 \mathrm{~b}$ shows that the ratio of the two values (U/US) was $0.80-1.62$, with an average of 1.19 . These results indicated that the pores inside the particles allow the

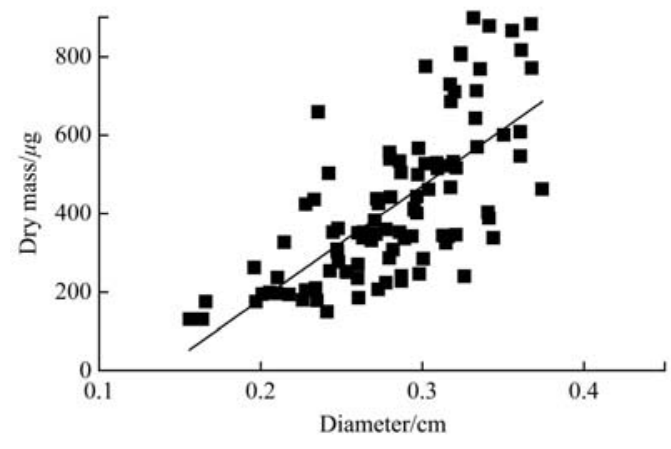

a. Dry mass passage of fluids, resulting in the increase of their settling velocity. Thus, the granular sludge had excellent settling velocity. Figure $9 \mathrm{c}$ shows that the average fluid collection efficiency of the granular sludge $(\eta)$ was 0.52 . $\mathrm{Li}$ and $\operatorname{Logan}^{[19]}$ found that the settling velocity of the fractal particles generated from the aggregation of latex microspheres $(2.84 \mathrm{~mm})$ can be two times greater than that of impermeable particles predicted by Stokes' law, for which the fluid collection efficiency was in the range of $0.08-0.83$ with an average of 0.5. This result is close to the fluid collection efficiency of the granular sludge in the present study. Therefore, the unevenly distributed large and small pores in the granular sludge cultivated in the UASB reactor allow the passage of liquid through the inside of the granular sludge, thus affording certain permeability to the granular sludge.

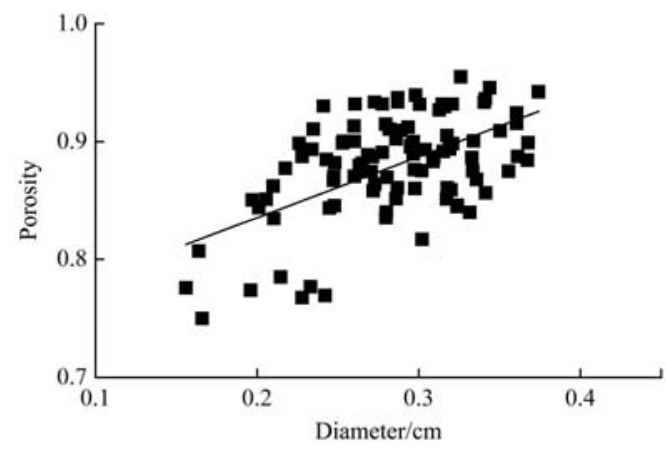

b. Porosity

Figure 8 Dry mass (a) and the average porosity (b) as a function of the size

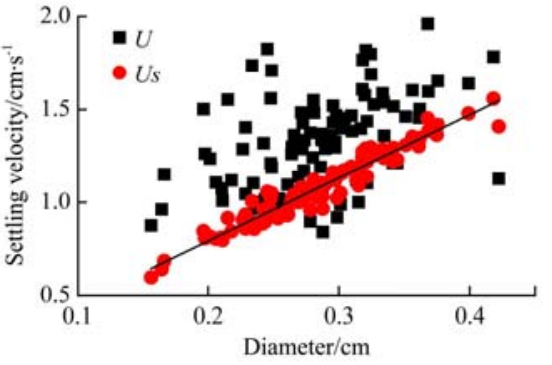

a. Settling velocity

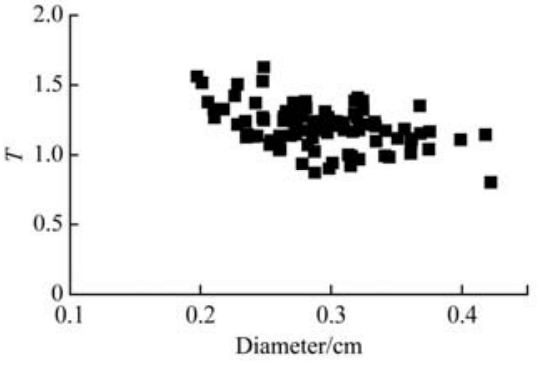

b. Ratio of observed and predicted settling velocities

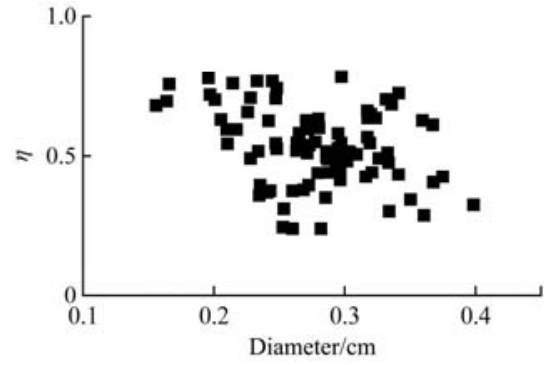

b. Fluid collection efficiency

Figure 9 Granular sludge: (a) settling velocity, (b) ratio of observed and predicted settling velocities and (c) fluid collection efficiency

\subsection{Shear strength of granular sludge}

The shear sensitivity $\left(K_{s s}\right)$ is normally used to describe the shear strength of granular sludge ${ }^{[14]}$. In the granular sludge formation process, under multiple selection pressures, such as high hydraulic shear, the particle structure generated from the aggregation of the head-tail connecting bacterial had high strength and excellent capacity to resist the impact load. The shear test in the present study is focused on the shear sensitivity analysis of the granular sludge under the shear strength of $800 \mathrm{~s}^{-1}$. The total solid concentration of the granular sludge suspension was $4.0 \mathrm{~g} / \mathrm{L}$. Figure 10 shows the time dependence of the equilibrium concentration of colloidal particles of granular sludge supernatant and the fitting curve. The corresponding shear sensitivity parameters are listed in Table 2; the fitted $K_{s s}$ was 0.1152 . Wang et al. ${ }^{[27]}$ performed analysis of the shear stability for anaerobic granular sludge and obtained a $K_{s s}$ of 0.4602 for the anaerobic methanogenic granular sludge under the same shear strength; thus, the granular sludge had much higher shear strength. Therefore, the granular sludge cultivated in this study had excellent shear stability. Furthermore, we proved that the mesh structure of the granular sludge and EPS produced from bacterial metabolism improved the adhesion among bacteria, thus increasing the structural stability of granular sludge.

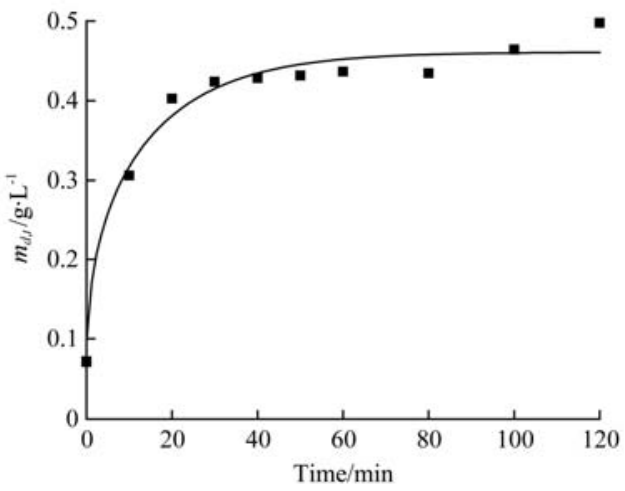

Figure 10 Typical erosion curves for granular sludge

Table 2 Corresponding shear sensitivity parameters of granular sludge

\begin{tabular}{ccccc}
\hline Parameters & $m_{T} / \mathrm{g} \cdot \mathrm{L}^{-1}$ & $m_{d, \infty} / \mathrm{g} \cdot \mathrm{L}^{-1}$ & $K_{s s}$ & $D / \mathrm{s}^{-1}$ \\
\hline Granular sludge & 4 & 0.4609 & 0.1152 & 0.0548 \\
\hline
\end{tabular}




\section{Conclusions}

The UASB reactor was used to cultivate hydrogen-producing granular sludge that is advantageous to the stable operation of fermentation system. The granulation of sludge underwent four stages, i.e., flocculation of sludge, formation of flocculent sludge, swelling of flocculent sludge, and formation of granular sludge. The whole process lasted approximately $70 \mathrm{~d}$; the hydrogen yield in the stable stage was $1.09 \mathrm{~mol} \mathrm{H}_{2} / \mathrm{mol}$ glucose.

The formation mechanism of granular sludge was that the hydrogen-producing and acid-producing bacteria existed as head-tail connected line structures after metabolism and reproduction; the line structures were wound together under the fluid flow and the adhesion of EPS, forming a mesh structure with a clear hierarchy. At the same time, other hydrogen-producing and acid-producing bacteria used the mesh structure as support for reproduction and growth, forming the structurally stable and regularly shaped granular sludge.

The fluid collection efficiency $(\eta)$ of the granular sludge was 0.54 , and the shear sensitivity (Kss) of the particles was 0.1152 . Therefore, the granular sludge cultivated in the UASB reactor had fractal structures with a regular shape, faster settling velocities, excellent permeabilities, and high shear strengths.

\section{Acknowledgements}

The authors are grateful to the financial support by National Natural Science Foundation of China (Grant No. 51506027) and "Young Talents" Project of Northeast Agricultural University (Grant No. 16QC18)

\section{[References]}

[1] Liu S, Wang C Y, Yin L L, Luo L N. Optimization of hydrogen production from agricultural wastes using mixture design. Int J Agric \& Biol Eng, 2017; 10(3): 246-254

[2] Li Q, Guan Z, Zheng G. Microorganism population in two-phase anaerobic fermentation of separated liquid of dairy manure. Int J Agric \& Biol Eng, 2018; 11(1): 206-211.

[3] Hsu C W, Lin C Y. Commercialization model of hydrogen production technology in Taiwan: Dark fermentation technology applications. International Journal of Hydrogen Energy, 2016; 41: 4489-4497.

[4] Lettinga G, Velsen A F M V, Hobma S W, Zeeuw W D, Klaplijk A. Use of the upflow sludge blanket (USB) reactor concept for biological wastewater treatment, especially for anaerobic treatment. Biotechnology \& Bioengineering, 1980; 22: 699-734.

[5] Hulshoff Pol L W, Si D C L, Lettinga G, Lens P N L. Anaerobic sludge granulation. Water Research, 2004; 38: 1376-1389.

[6] Yang M, Yu H Q. Biological hydrogen production in a UASB reactor with granules. I: Physicochemical characteristics of hydrogen-producing granules. Biotechnology \& Bioengineering, 2006; 94: 980-987.

[7] Guiot S R, Pauss A. A structured model of the anaerobic granule consortium. Water Science \& Technology, 1992; 25: 1-10.

[8] Zinatizadeh A A, Mirghorayshi M, Birgani P M, Mohammadi P, Ibrahim S Influence of thermal and chemical pretreatment on structural stability of granular sludge for high-rate hydrogen production in an UASB bioreactor.
International Journal of Hydrogen Energy, 2017; 42: 20512-20519.

[9] Show K Y, Zhang Z P, Tay J H, Liang D T, Lee D J. Production of hydrogen in a granular sludge-based anaerobic continuous stirred tank reactor. International Journal of Hydrogen Energy, 2007; 32(18): 4744-4753.

[10] Ruhl A S, Jekel M. Influence of hydronium, sulfate, chloride and other non-carbonate ions on hydrogen generation by anaerobic corrosion of granular cast iron. Water Research, 2013; 47(16): 6044-6051.

[11] Hao X L, Zhou M H, Yu H Q, Shen Q Q, Lei Y C. Effect of sodium ion concentration on hydrogen production from sucrose by anaerobic hydrogen-producing granular sludge. Chinese Journal of Chemical Engineering, 2006; 14(4): 511-517. (in Chinese)

[12] Saady N M C, Chaganti S R, Lalman J A, Veeravalli S S, Shanmugam S R. Assessing the impact of palmitic, myristic and lauric acids on hydrogen production from glucose fermentation by mixed anaerobic granular cultures. International Journal of Hydrogen Energy, 2012; 37(24): 18761-18772.

[13] Li X Y, Yuan Y. Settling velocities and permeabilities of microbial aggregates. Water Research, 2002; 36: 3110-3120.

[14] Sheng G P, Yu H Q, Li X Y. Stability of sludge flocs under shear conditions. Biochemical Engineering Journal, 2008; 38: 302-308.

[15] Jung K W, Cho S K, Yun Y M, Shin H S, Kim D H. Rapid formation of hydrogen-producing granules in an up-flow anaerobic sludge blanket reactor coupled with high-rate recirculation. International Journal of Hydrogen Energy, 2013; 38: 9097-9103.

[16] APHA. Standard methods for the examination of water and wastewater, 20th Ed. American Public Health Association, 2004.

[17] Tansel B, Nagarajan P. SEM study of phenolphthalein adsorption on granular activated carbon. Advances in Environmental Research, 2004; 8(3): 411-415

[18] Jiang Q, Logan B E. Fractal dimensions of aggregates determined from steady-state size distributions. Environmental Science \& Technology, 1991; 25: 2031-2038.

[19] Li X Y, Yuan Y. Collision frequencies of microbial aggregates with small particles by differential sedimentation. Environmental Science \& Technology, 2002; 36: 387-393.

[20] Rani R U, Kumar S A, Kaliappan S, Lcktae Y, Banu J R. Low temperature thermo-chemical pretreatment of dairy waste activated sludge for anaerobic digestion process. Bioresource Technology, 2012; 103: 415-424.

[21] Hulshoff Pol L W, van de Worp J J M, Lettinga G, Beverloo. Physical characterization of anaerobic granular sludge. Proc, 1986; 265: 8205-8211.

[22] Simon S, Païro B, Villain M, D’Abzac P, Hullebusch E V, Lens P, et al. Evaluation of size exclusion chromatography (SEC) for the characterization of extracellular polymeric substances (EPS) in anaerobic granular sludges. Bioresource Technology, 2009; 100: 6258-6268.

[23] Liu X M, Sheng G P, Yu H Q. DLVO Approach to the flocculability of a photosynthetic $\mathrm{H}_{2}$-producing bacterium, Rhodopseudomonas acidophila. Environmental Science \& Technology, 2007; 41(13): 4620-4625.

[24] Noyola A, Moreno G. Granule production from raw waste activated sludge. Water Science \& Technology, 1994; 30: 339-346.

[25] Zhou D Q. Microbiology course. Beijing: Higher Education Press, 2011. (in Chinese)

[26] Hulshoff Pol L W, Zeeuw W J, Velzeboer C T M, Lettinga G. Granulation in UASB-reactors. Water Science \& Technology, 1983; 15: 291-304.

[27] Wang Y L, Huang C G. Analysis of the shear stability of aerobic sludge flocs and anaerobic sludge granules. China Environmental Science, 2009; 9: 341-344. (in Chinese) 